\title{
Orthogonal Experimental Study on Heat Transfer Optimization of Backfill Slurry with Ice Particles
}

\author{
Mei Wang $\mathbb{D},{ }^{1,2}$ Peng Liu, ${ }^{1}$ Yuhang Jia, ${ }^{3}$ Yujiao Zhao, ${ }^{1,2}$ and Bo Zhang $\mathbb{D}^{1,2}$ \\ ${ }^{1}$ Energy School, Xi'an University of Science and Technology, Xi'an 710054, China \\ ${ }^{2}$ Key Laboratory of Western Mines and Hazards Prevention, Ministry of Education of China, Xi'an 710054, China \\ ${ }^{3}$ Yulin Municipal Bureau of Housing and Urban-Rural Development, Yulin, China \\ Correspondence should be addressed to Mei Wang; wangmei029@xust.edu.cn
}

Received 25 December 2020; Revised 10 March 2021; Accepted 30 April 2021; Published 11 May 2021

Academic Editor: Jin Luo

Copyright (C) 2021 Mei Wang et al. This is an open access article distributed under the Creative Commons Attribution License, which permits unrestricted use, distribution, and reproduction in any medium, provided the original work is properly cited.

To reduce the risk of high-temperature geothermal environment in deep mine exploitation, an innovative method for cooling stopes by backfill slurry with ice particles has been focused on. In this paper, aiming at the cooling effect of backfill slurry with ice particles, an experimental device including stope region and ice-filled filling slurry region was established for temperature measurement experimental simulation study. The results showed the ice-filled slurry had a significant cooling effect on the stope region. Orthogonal design experiment and range analysis methods were applied for studying the influencing regularities of four factors, including boundary heat flux, ice-water ratio, sand-cement ratio, and slurry concentration. The effective cooling heat coefficient which is defined by radiation heat flux and boundary heat flux of surrounding rock was applied as an evaluation index for scheme optimization. The influencing rank of the four factors is boundary heat flux $>$ sand-cement ratio $>$ ice-water ratio $>$ slurry concentration. By comprehensive analysis, the optimization of mixture ratio was obtained: the boundary heat flux of the simulated surrounding rocks is $111 \mathrm{~W} / \mathrm{m}^{2}$, the ratio of ice to water is $8: 5$, the ratio of sand to cement is $4: 1$, and the slurry concentration is $64 \%$.

\section{Introduction}

Mining frequently causes surface collapse, tailings' waste accumulation, and other problems, causing serious damage to the environment $[1,2]$. The in-depth development trend of mine resource exploitation has aggravated the problem of thermal damage in mines, which not only seriously affects the safety production efficiency of mining enterprises and physical or mental health of underground workers, but also affects the progress of mine transformation and upgrading [3-5]. It is important for solving the heat hazard problem in deep mines and creating the overall proper temperature environment of the stope to acquire obvious economic and safety benefits.

In view of the above problems, cemented paste backfill technology has the advantages in mining safety and tailings' waste utilization. It has a positive significance in the realization of green mining [6-9]. As heat hazard becomes a pivotal obstacle in deep mine, Wang et al. proposed a cooling method with ice-filled slurry based on the traditional cemented paste backfill technology $[10,11]$. Compared with the traditional cemented paste backfill, ice-filled backfill has the capability of mine thermal hazard control, which is expected to solve heat hazard problems in mining. Traditional cemented paste backfill mainly includes tailings, cement, and water. Tailings are used as aggregates; cement are used as cementitious material. In the ice-filled backfill, ice particles with a diameter of about $3 \sim 5 \mathrm{~mm}$ are used instead of part of the water, which will absorb heat during the melting process in the goaf underground. The ratio of cemented paste backfill slurry will affect the mechanical properties of the filling body, such as strength, collapse degree, and fluidity, and the thermal properties such as temperature and heat flux [12]. Zhang et al. experimentally studied the distribution law of the internal temperature inside the ice-filled slurry, and the results showed that the 
mechanical properties of the ice-filled slurry backfill were enhanced to a certain extent. The addition of PCM will affect the compressive strength thermal conductivity and the specific heat capacity $[13,14]$. Wang et al. used CFD simulation and experiment to study the temperature distribution characteristics in the ice-filled filling body, thus verifying the consistency of simulation and experiment. Fang studied the rheological properties, pore structure, and mechanical properties of the ice-filled filling slurry and found that the ice-filled filling slurry has good flow transmission characteristics in the pipe [15]. Although ice-filled backfill has a unique cooling effect and great potential in deep well cooling, there is still a lack of research on the optimizing proportion of ice-filled filling slurry and illustrating the relationship between the cooling effect and the proportion at present.

For optimizing proportion research, the formula design of the traditional backfill material could be used for reference. Hu et al. established an optimization performance of filling slurry and cemented body and verified it by means of uniform experiment. The experimental results showed that the optimal parameters of the filling slurry were the mass concentration of slurry $72 \%$ and the ratio of sand to cement $4: 1$ [16]. Fan et al. carried out the basic test for evaluating the backfill performance of unclassified tailings and the orthogonal ratio test. The study showed that the mass concentration of unclassified tailings slurry should be higher than the critical value at $1: 4$ and $1: 8$. Making the filling slurry close to the paste body is beneficial to improving the strength of the filling body [17]. Through the rheometer test, numerical simulation test of pipeline transport characteristics, analysis of filling strength, and uniaxial compression test, Men et al. presented two proportions (the concentration of $71 \%$, the cement-sand ratio of $1: 8-1: 10$ and the concentration of $73 \%$ and the cementsand ratio of $1: 10)$ that could satisfy the requirements of filling strength, fluidity, and pipeline transport resistance loss [18]. Contrastive analysis showed that the optimal combination was sand-cement ratio 1:5 and mass concentration $69 \%$. The studies above have made outstanding contributions to such issues as strength of filling materials, economy of filling mining, transportation mode of filling slurry, and fluidity of filling materials. However, there is no research on optimizing proportion of filling slurry with ice particles yet.

Orthogonal experiments method vastly reduces the number of tests and makes the whole process relatively easy and fast $[19,20]$. Therefore, it is advisable that orthogonal experiments are used to optimize the ratio of ice-filled filling slurry. Fall and Benzaazoua designed an orthogonal experiment including six factors and five levels and took uniaxial compressive strength as the evaluation index [21]. When analyzing the solid-liquid phase of cement backfill, Liu et al. investigated more appropriate slurry concentration, tailings' particle size, and sand-cement ratio by used orthogonal test $[22,23]$. The influence of various factors should be considered in the design and study of ice-filled slurry backfill. Therefore, orthogonal design tests can also be used in the experimental design.
At present, most of the studies on cemented paste backfill slurry are evaluated from the aspects of strength and flow performance to determine the optimal ratio. The existing research of strength and flow characteristics at different ratios provides a basis for the development of experimental schemes for researching ice-filled filling backfill [24]. Wei found that the sample temperature of cemented backfill was positively correlated with slurry concentration, sand-cement ratio, and volume [25]. In order to illustrate the cooling effect of ice-filled backfill, thermal properties could be selected as the evaluation index. For the ice-filled slurry filling region and stope region, the thermal environments are influenced by multiple factors. As far as stope region is concerned, its internal temperature field is influenced by a series of internal and external factors, such as the load capacity of ice-filled slurry filling region, temperature of surrounding rock, heat released by mechanical equipment, et al. The temperature field of stope region main influenced by the cold radiation effect of ice-filled region and the thermal radiation effect of surrounding rock [26, 27]. Therefore, the existing research on radiant floor cooling can be used for reference.

According to the previous research, the orthogonal experimental scheme of ice-filled backfill was designed from the thermal perspective for studying the ratio optimization of ice-filled slurry. By measuring real-time temperature data, the heat transfer performance was obtained under different conditions. The evaluation index was put forward for choosing optimized scheme of multiple factors and level. Finally, the optimal ratio of ice-filled filling slurry was obtained by processing and statistical analysis of the experimental data.

\section{Materials and Methods}

2.1. Introduction to Experimental Materials. In the process of preparation of ice-filled slurry, it is necessary to meet the relevant standards of backfill technology. During the configuration of ice-filled slurry, ice particles are used to replace part of the water. When ice particles are used instead of water, the initial slurry concentration will be increased and the fluidity of the slurry will be affected. The traditional slurry concentration is generally between $70 \%$ and $76 \%$ [28]. In order to ensure the fluidity of slurry and strength of backfill, the concentration of the ice-filled slurry is controlled between $64 \%$ and $72 \%$. In the experiment, the tailings of a gold mine were used as aggregates, and the tailings were screened by sandstone sieve with an aperture of $0.35 \mathrm{~mm}$. P.O. 42.5 Portland Cement is used as cementing material. The diameter of the ice particles used is about $3 \mathrm{~mm}$. The physical parameters of the material used are shown in Table 1.

2.2. Experimental Device. The experimental device is designed for simulating the stope region and the ice-filled slurry filling region, as shown in Figure 1(a). The main devices and equipment in the system were the experimental box body composed of aluminum plate and the rubber 
Table 1: Material specifications.

\begin{tabular}{lccc}
\hline Materials & Density $\left(\mathrm{kg} / \mathrm{m}^{3}\right)$ & Specific heat $(\mathrm{J} / \mathrm{kg} \cdot \mathrm{K})$ & Thermal conductivity $(\mathrm{W} / \mathrm{m} \cdot \mathrm{K})$ \\
\hline Water & 1000 & 4200 & 0.5638 \\
Ice particles & 917 & 2100 & 2.2 \\
Tailings & 3500 & 1090 & 3.2 \\
Cement & 2800 & 840 & 0.6 \\
\hline
\end{tabular}

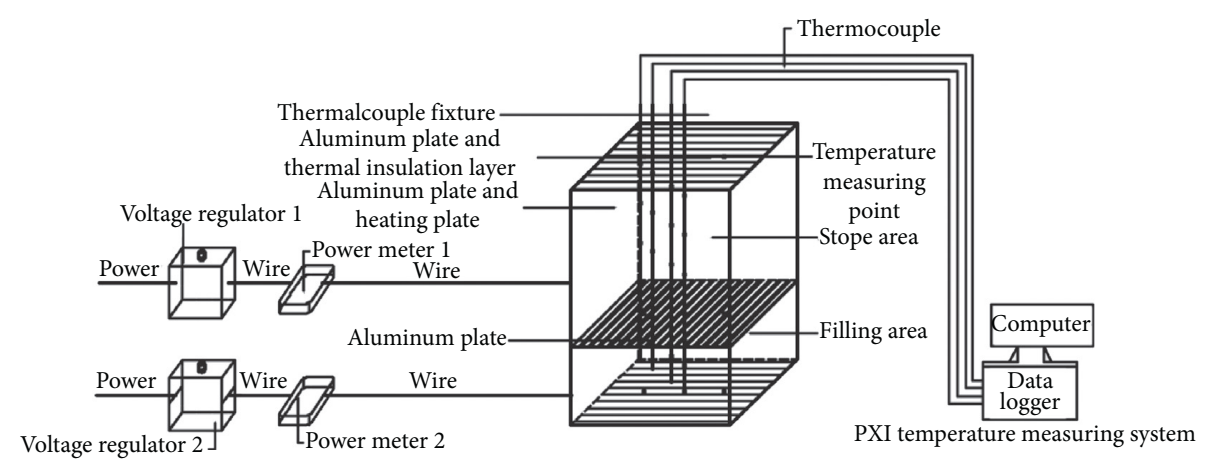

(a)

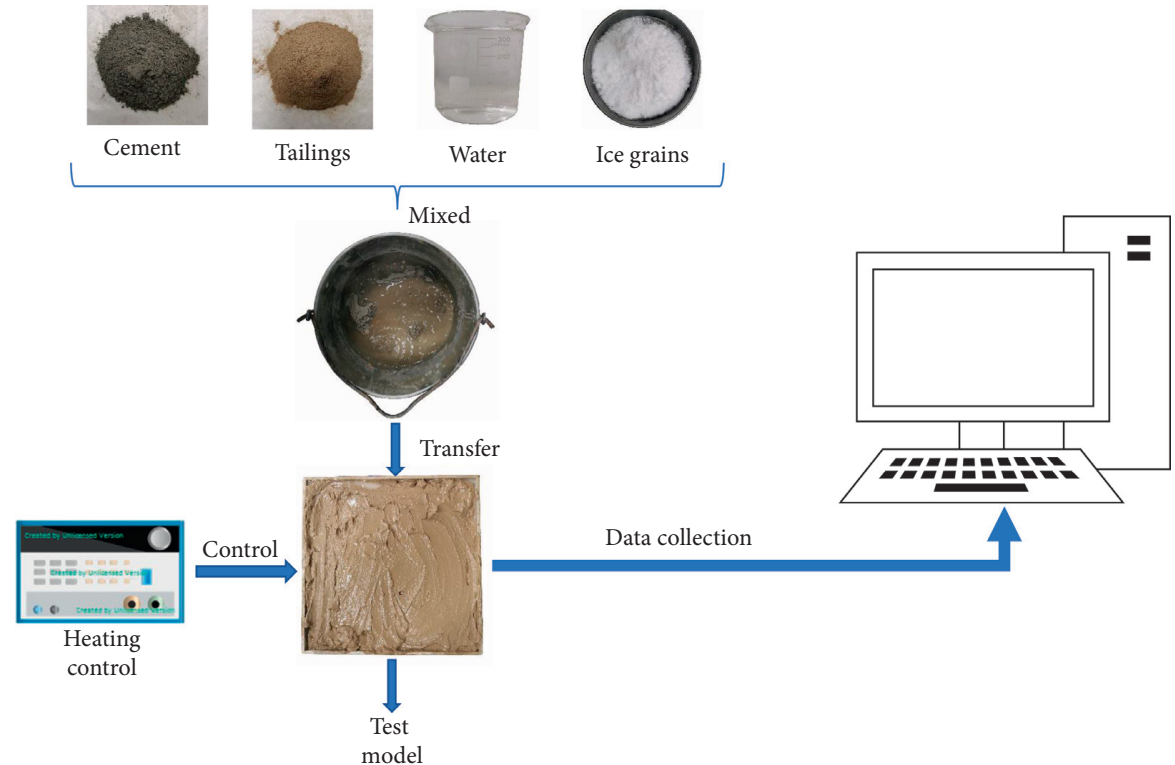

(b)

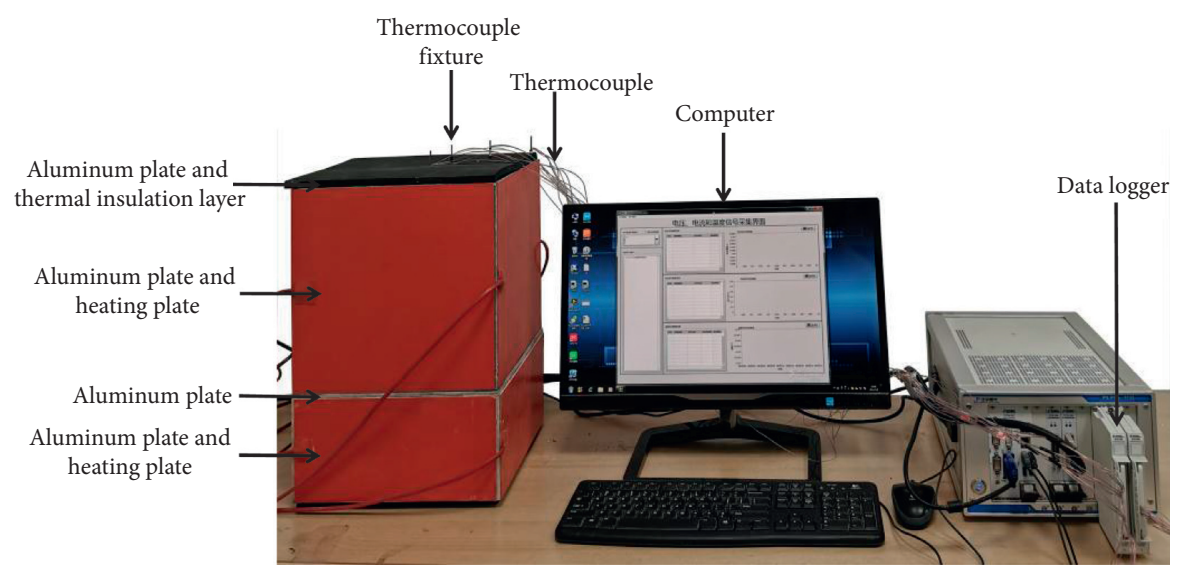

(c)

FIgURE 1: Experimental apparatus. (a) Schematic diagram of the experimental system. (b) Experiment flow graph. (c) Pictures of the experimental system. 
heating plate. Installed inside the experimental box body were K-type thermocouples, and on the outside rubber heating plate and insulation board were connected. The whole box was linked to a National Instruments PXI temperature measurement system. The uncertainty of the whole temperature measurement system is about $0.38 \mathrm{~K}$. The relative component information was summarized in Table 2. The experiment box consists of two different regions by the middle partition. The upper part is the simulated stope region $(300 \times 300 \times 300 \mathrm{~mm})$ which is filled with air. The lower part is the ice-filled slurry filling region with a size of $300 \times 300 \times 150 \mathrm{~mm}$. In order to facilitate the arrangement of temperature measuring points inside the box, the holes for thermocouples to penetrate the box are reserved on the upper surface and the middle partition, respectively.

In the experiment, the thermal environment in the simulated stope region and the ice-filled slurry filling region were influenced by the thermal flux of boundary heating, the internal material phase change, and hydration. In the preparation stage of the experiment, the required materials were prepared and weighed. During the experiment, the required materials are added to the mixing device in turn, each group of the experiment is stirred for 15 minutes, and the slurry in the stirring device is fully mixed evenly. The mixed experimental slurry is transferred to the experimental test model; the boundary condition control device and data acquisition device are activated for measurement, as shown in Figure 1(b). The temperature data in the two regions are obtained by setting up multiple temperature monitoring points. Based on the temperature trend, the heat transfer characteristics of simulated stope region and the ice-filled slurry filling region under four different conditions can be analyzed. Vertical rods are used to hold the K-type thermocouples distributed between the two areas. As shown in Figure 1(c), the aluminum plate around the box is attached to heating plate to simulate the condition of constant heat flux. The heating plate is controlled by two sets of heat adjusting devices in the upper and lower regions. Each set of heat flux regulator is consisting of voltage regulator, power meter, and wire. By adjusting the output voltage, the heating power of the heating plate is controlled to achieve the boundary condition of constant heat flux.

In order to show the characteristics of temperature variations in different regions during the experiment, the ice-filled slurry filling region, the simulated stope region, and the external environment temperature measuring points were arranged, respectively, to carry out continuous temperature measurements.

As shown in Figure 2(a), the measuring points in the box are arranged in different ways, according to the positions' characteristics. The measuring points in the suspended position in the box are fixed on the vertical column. The measuring points of 21\#-23\#, 24\#-26\#, 27\#-29\# are arranged, respectively, in the upper, middle, and lower aluminum plates for measuring the aluminum inside surface temperature. The measuring points $30 \#$ and $31 \#$ are arranged, respectively, on the outer surface of the upper and lower insulating materials. In addition, the measuring point $32 \#$ is set outside the device to measure the ambient temperature. Figure 2(b) shows the spatial arrangement of the measurement points. There are five measuring points on each vertical rod. There are $1 \#-3 \#$ measuring points in the simulated stope region, and 4\#-5\# measuring points in the filling region; the distance of each point is shown in Figure 2(b).

2.3. Orthogonal Experimental Method. Orthogonal experiment is a mathematical method of multifactor experimental analysis based on statistical principle and orthogonal theory. When conducting orthogonal experiment, typical and representative experimental samples should be selected for sufficient experiment to analyze the influence of various factors on different experimental results [29-31]. The orthogonal test table is the basis of orthogonal test design. When selecting different influencing factors and levels, different orthogonal test tables were adopted, and corresponding orthogonal experimental schemes were obtained. Orthogonal experiment can effectively reduce the experiment cost and time, so it is widely used in daily study and research work.

In the preparation of the filling slurry, the main influencing factors include slurry concentration and sand-cement ratio $[32,33]$. In this paper, in order to study the change of thermal performance of ice-filled slurry with different proportions, it is necessary to take the boundary heat flux of simulated surrounding rock and the ice-water ratio as influencing factors. Finally, four influencing factors including the boundary heat flux, the ice-water ratio, the sand-cement ratio, and slurry concentration are selected, and three different levels are set for each influencing factor. According to the preliminary estimation of the influence degree of each influencing factor on the thermal performance, the influencing factors are arranged from the largest to the smallest, as shown in Table 3. According to the selected factors and the number of levels, the L9 (34) orthogonal test table is determined.

2.4. Evaluation Indicators. In order to compare the cooling effect under different influencing factors, the comprehensive evaluation index was needed to be put forward. Heat flux in the simulated stope region included the boundary heat flux of simulated surrounding rock and the cold radiation heat flux. Therefore, the comprehensive evaluation index and effective cooling heat coefficient $\eta$ can be defined as

$$
\eta=\frac{\int_{0}^{t}\left|q_{r}\right|}{\int_{0}^{t} q_{r}+\int_{0}^{t} q_{h}},
$$

where $q_{r}$ is cold radiation heat flow, $\mathrm{W} / \mathrm{m}^{2}$, and the calculation formula is shown in equation (2), $q_{h}$ is the boundary heat flux of simulated surrounding rock, $\mathrm{W} / \mathrm{m}^{2}$ [34].

$$
q_{r}=\varepsilon \sigma\left(T_{2}^{4}-T_{25}^{4}\right),
$$

where $T_{2}$ represents the temperature at $2 \#$ measurement point, $T_{25}$ represents the temperature at $25 \#$ measurement point, $\varepsilon$ represents the radiation emissivity of the middle 
TABLE 2: Temperature measurement system.

\begin{tabular}{lccc}
\hline Component & Manufacturer & Model & Precision \\
\hline Thermocouple & Omega & TT-K-30 & $\pm 0.5 \mathrm{~K}$ \\
PXI & National Instruments & PXIe-4353 & $\pm 0.3 \mathrm{~K}$ \\
\hline
\end{tabular}

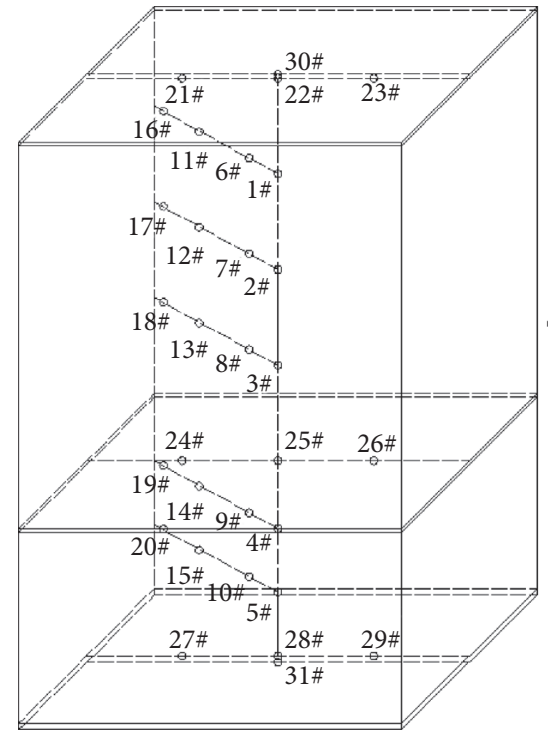

(a)

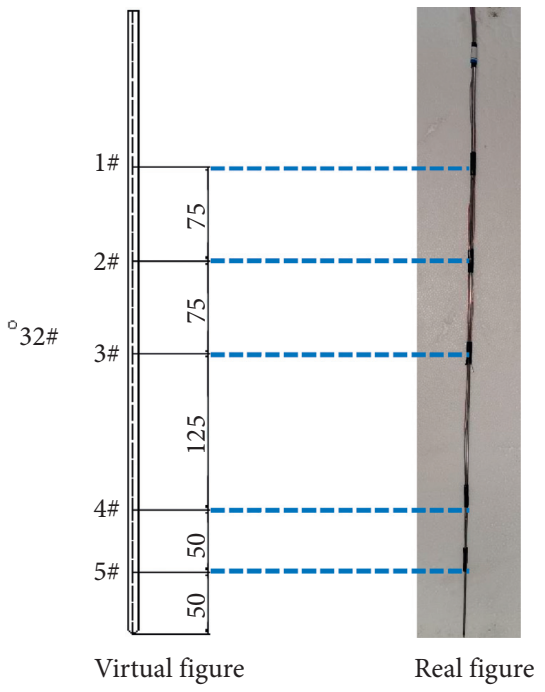

(b)

Figure 2: Arrangement of measuring points. (a) The arrangements of thermocouples. (b) The longitudinal arrangement of thermocouples.

TABLE 3: Factors and levels in the orthogonal experiment.

\begin{tabular}{|c|c|c|c|c|}
\hline \multirow{2}{*}{ Item } & \multirow{2}{*}{ Factors } & \multicolumn{3}{|c|}{ Levels } \\
\hline & & 1 & 2 & 3 \\
\hline A & Boundary heat flow $\left(\mathrm{W} / \mathrm{m}^{2}\right)$ & 111 & 333 & 555 \\
\hline B & Ice-water ratio & $2: 5$ & $5: 5$ & $8: 5$ \\
\hline $\mathrm{C}$ & Sand-cement ratio & $4: 1$ & $6: 1$ & $8: 1$ \\
\hline $\mathrm{D}$ & Slurry concentration (\%) & $64 \%$ & $68 \%$ & $72 \%$ \\
\hline
\end{tabular}

partition, and the radiation emissivity of the aluminum plate is 0.2 , and $\sigma$ presents the Stefan-Boltzmann constant, $5.67 \times 10^{-8} \mathrm{~W} /\left(\mathrm{m}^{2} \cdot \mathrm{K}^{4}\right)$.

For underground working environment, according to the "Technical Specification for Metal Ventilation System of Metallic and Non-Metallic Underground Mines in China," the air temperature at the underground working site shall not exceed $301 \mathrm{k}$ [35]. Therefore, $301 \mathrm{k}$ is taken as the reference line for comparison under different heat flux densities.

The Stephen number indicates the ratio of sensible heat to latent heat in the ice-filled filling slurry region. Sensible heat refers to any object in the process of absorbing or releasing heat; its shape does not change, but the temperature changes. Latent heat refers to the change in the form of the substance in the process of heat absorption or heat release, but the temperature does not change; that is, the added heat cannot be displayed on the thermometer [36-38]. The calculation of Stephen number is shown in the following equation [39]:

$$
\text { Ste }=\frac{c_{s}\left(T_{m}-T_{0}\right)}{m_{i} L}
$$

where the temperature difference can be obtained by equations (4) and (5), representing the relationship between the thickness and width of ice-filled slurry backfill [34]:

$$
\begin{gathered}
q_{h}=\frac{\lambda_{s} \Delta T}{\delta}, \\
D=2 \delta .
\end{gathered}
$$

Thus, Stephen's number formula of heat flux is obtained as follows:

$$
\text { Ste }=\frac{c_{s} q_{h} D /\left(2 \lambda_{s}\right)}{m_{i} L}
$$

where $c_{s}$ is the specific heat capacity of the ice-filled slurry, $1.544 \mathrm{~kJ} /(\mathrm{kg} \cdot \mathrm{K}) . D$ is the width of the bottom device, $0.3 \mathrm{~m} . \lambda_{s}$ is the thermal conductivity coefficient of the ice- 
filled slurry, $0.6761 \mathrm{~W} /(\mathrm{m} \cdot \mathrm{K}), m_{i}$ is the mass fraction of ice particles, and $L$ is the latent heat of ice, $3.35 \times 10^{2} \mathrm{~kJ} / \mathrm{kg}$.

\section{Temperature Field Distribution Characteristics}

In the experiment, the thermal environment in the simulated stope region and the ice-filled slurry filling region were influenced by the boundary heat flux, the phase transition, and hydration of the internal materials. The multipoints temperature data were obtained by setting multiple temperature monitoring points in the two regions. According to the variation process of the temperature data, the heat transfer characteristics of the simulated stope region and the ice-filled slurry filling region under the condition of four different influencing factors can be analyzed.

\subsection{Temperature Characteristics of Simulated Stope Region} under Different Boundary Heat Flux Conditions. Based on industrial field practice, Saito et al. studied the relationship between heat transfer surface and phase change boundary of ice under different boundary heat flux, indicating that ice would be affected by heat flux under constant action [40]. Boundary heat flux cannot be fixed in each mine. Through simulating different boundaries heat flux boundary, the stope cooling rate is obtained.

As shown in Figure 1(a), to ensure that the heat of the heating plate is transferred to the simulated stope region and the ice-filled slurry region without heat loss to the environmental, the top and bottom of the experimental device and outside of the rubber heating plate are covered with an adiabatic plate. Three different boundary heat flux densities are designed in the orthogonal experiment scheme, as shown in Table 3. At the same time, the experiment condition of boundary heat flux of $0 \mathrm{~W} / \mathrm{m}^{2}$ was designed for reference, which simulated the boundary condition of the surrounding rock as an adiabatic and taken as the no-treatment condition.

In the experiment, the first experimental data obtained is defined as the initial temperature. Figure 3 shows the realtime temperature of the $2 \#$ measuring point in the simulated stope region, and the temperature is obtained under four different boundary heat flux densities and the same ice-water ratio $(2: 5)$. The initial temperature of stope in the experiment is close to the ambient temperature. Over the same period, the simulated temperature extremum in stope region has a lot of difference under the different boundary heat flux condition. The temperature extremum obviously increases with the boundary heat flux. When $q_{h}=111 \mathrm{~W} / \mathrm{m}^{2}$, the temperature in the simulated stope region is always lower than $301 \mathrm{k}$ during the experiment time. With increasing of the heat flux, the temperature of the simulated stope area will exceed the specified value. For $q_{h}=333 \mathrm{~W} / \mathrm{m}^{2}$, the duration of temperature below $301 \mathrm{k}$ in the simulated stope area is about $30 \mathrm{~min}$, while for $q_{h}=555 \mathrm{~W} / \mathrm{m}^{2}$, the duration is about $15 \mathrm{~min}$. It can be concluded that large boundary heat flux will greatly affect the cooling effect of ice-filled slurry filling on stope.
Figure 4 shows the temperature difference $T^{*}$ over time between the real-time temperature and the initial temperature of the measuring point 2\# under four different boundary heat flux and four same ice-water ratio $(2: 5)$ conditions. For the case that the boundary was not heated, $q_{h}=0 \mathrm{~W} / \mathrm{m}^{2}, T^{*}$ was negative which means the real-time temperature of $2 \#$ was lower than the initial temperature during the entire process of the experiment. Owing to the ice particles melting and absorbing latent heat, the temperature of filling region increased. By the temperature difference between filling region and stope region, the amount of cooling was transferred to the stope region by means of radiation and heat conduction, and then the stope region was cooled.

At the onset of the experiments, the ice particles in the filling region gradually melt and absorbed plentiful heat, leading to the real-time temperature and temperature difference $T^{*}$ drop. While at the end of the experiment, the ice particles had melted, the cooling effect of latent cold diminish, and the temperature difference $T^{*}$ began to increase. However, the sensible cold was still transferring until the temperature in the stope region equals the filling region. The temperature difference $T^{*}$ was positive in most time periods except the initial stage under the condition of $q_{h}=111 \mathrm{~W} /$ $\mathrm{m}^{2}$. It indicates the heat absorbed by the stope area from the boundary was much larger than the cold absorbed from filling region. Therefore, the cooling capacity should be designed for different mines according to the thermal conditions in practice.

Comparing the results from different heat flux conditions, the higher the heat flux, the greater the temperature difference $T^{*}$. At the end of the experiment (time $=5 \mathrm{~h}$ ), the temperature difference $T^{*}$ under condition of $q_{h}=111 \mathrm{~W} / \mathrm{m}^{2}$ was $83.4 \%$ lower than under the condition of $q_{h}=555 \mathrm{~W} / \mathrm{m}^{2}$.

\subsection{Characteristics of Temperature Difference between the} Simulated Stope Region and the Ice-Filled Slurry Filling Region. In the experiment, the heat between simulated stope region and ice-filled slurry filling region was transferred by heat conduction, convection, and radiation. The temperature difference between the two regions largely determines the heat transfer efficiency. Therefore, it is essential to analyze the real-time temperature difference between the simulated stope region and the ice-filled slurry filling region.

The measuring points $2 \#$ and 5\# were selected as the core temperature points in the simulated stope region and the icefilled slurry filling region. The real-time temperature difference was calculated from the temperature difference in the core region, and the experiment conditions of boundary heat flux at $111 \mathrm{~W} / \mathrm{m}^{2}$, ice-water ratio at $2: 5$, sand-cement ratio at $4: 1$, and slurry concentration at $64 \%$ were taken as example for analysis. As shown in Figure 5, the temperature of 2\# measuring point gradually increased with time, and the temperature rising rate before $90 \mathrm{~min}$ is higher than that after $90 \mathrm{~min}$. The temperature change rate of $5 \#$ measuring point presents a trend that the temperature rising rate before $30 \mathrm{~min}$ is lower than that after $30 \mathrm{~min}$, which is contrary to the trend of the temperature rising rate of $2 \#$. In the early 


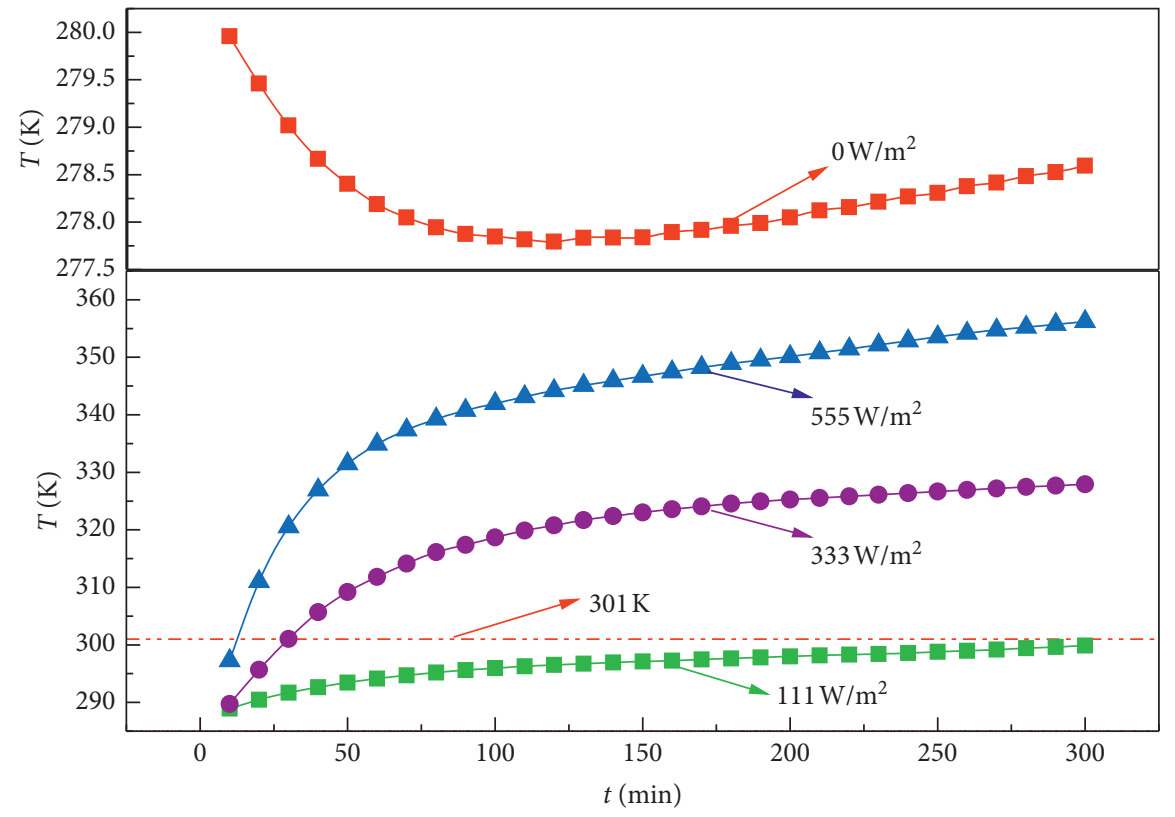

FIgURE 3: Temperature variations under different boundary heat flux.

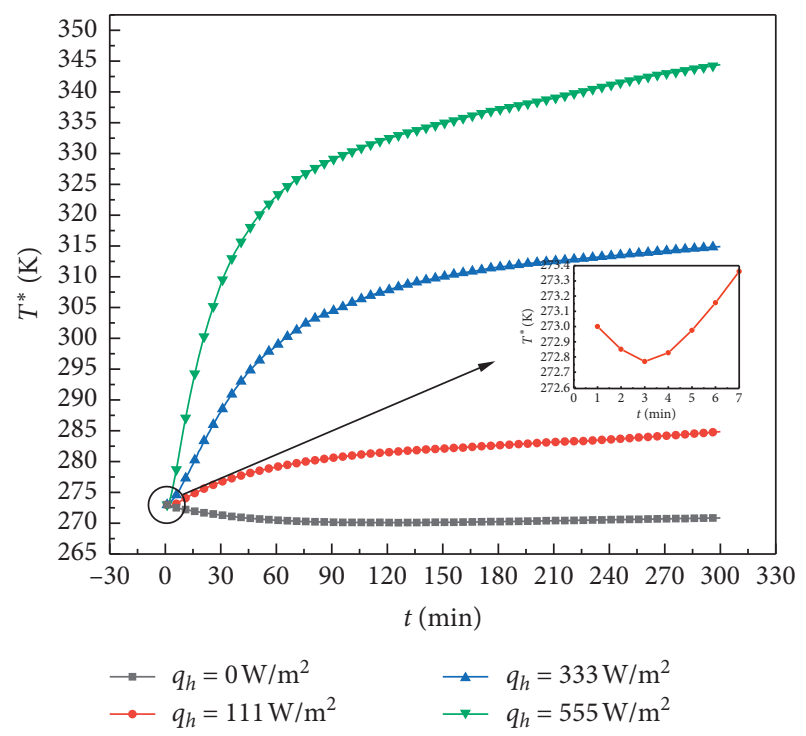

Figure 4: Temperature difference variations under different boundary heat flux.

stage of experiments, the heat transferred by the boundary heat flux would release heat to ice-filled slurry, and the melting ice particles would absorb heat from the ice-filled slurry. By the combination of these two effects, the temperature change range at this stage is very small.

For researching the boundary temperature difference of these two regions, measurement points of 17\# and 20\# were analyzed for stope region and filling region, respectively. As shown in Figure 5, the temperature of 17\# gradually increased with time and the temperature rising rate before $60 \mathrm{~min}$ was greater than that after $60 \mathrm{~min}$. The temperature of $20 \#$ also gradually increased, but the temperature rising rate generally tends to be stable with no obvious sign of

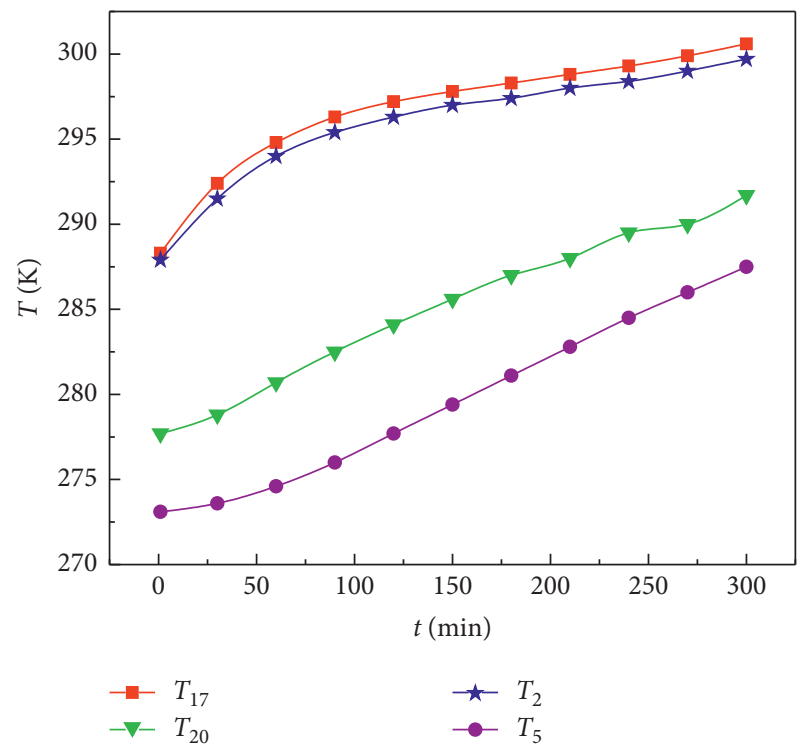

FIgURE 5: Temperature variations in the two regions.

increase or decrease, which is different from the trend of stope region.

Figure 6 shows that the temperature differences between the two regions both in boundary part and the core part have a similar trend. The temperature difference increased first and then decreased, reaching a maximum value around $60 \mathrm{~min}$ and $70 \mathrm{~min}$ for the boundary and the core, respectively. Obviously, the temperature difference between these two regions of core part was greater than the boundary part. This is because the simulated experiment took constant heat flux as boundary conditions. The boundary temperature was higher and less affected by the internal region heat transfer. For the core part, the boundary conditions influenced indirectly; meanwhile, ice particle melting absorbed heat in the 


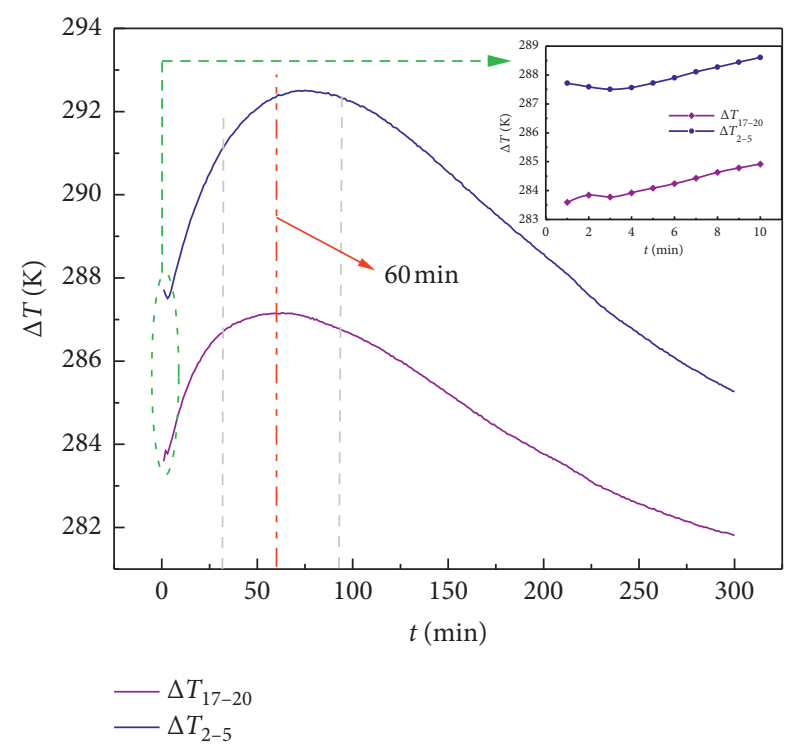

Figure 6: Temperature difference between the two regions.

filling slurry region, so the core temperature in the filling region with ice filling slurry is low, and the core temperature difference of two regions is larger.

3.3. Characteristics of Cold Radiant Heat in the Ice-Filled Slurry Filling Region. The cooling effect of backfill slurry with ice particles was influenced by the characteristics of backfill slurry and the thermal environment of the simulated stope. For the characteristics of backfill slurry, the cold capacity of backfill is related to ice-water ratio, sand-cement ratio, and slurry concentration. While for the thermal environment of simulated stope, the cooling effect is closely related to the boundary heat flux. These four factors were analyzed through experiment. In the experiment, the filling body containing ice slurry is below the stope, and the cold quantity is below the heat quantity. In this case, the cold radiation heat transfer is far greater than the convective heat transfer, so the convective heat transfer can be ignored.

According to equations (1) and (2), the effective cooling heat coefficient $\eta$ for each combination ratio experiment within $5 \mathrm{~h}$ can be calculated. On the basis of equation (1), the heat calculation needs to integrate the boundary heat flux and cold radiation heat flux, respectively. The boundary heat flux of simulated surrounding rocks was a constant value under each combination ratio, and the heat calculation was the integral of a constant function. In the calculation of cold radiation heat, the radiation calculation equation was integration and the real-time temperature data was used for integral calculation. The ratio consistent with the part of 3.2 was taken as an example, and the cold radiant heat of the cold is shown in Figure 7.

Figure 7 for different boundary heat flux of cold radiation heat flux, the area of the shaded part represents cold heat radiation. The change trend of cold radiation heat flux is consistent with the temperature difference curve changes. When the experiment runs for 60 minutes, temperature

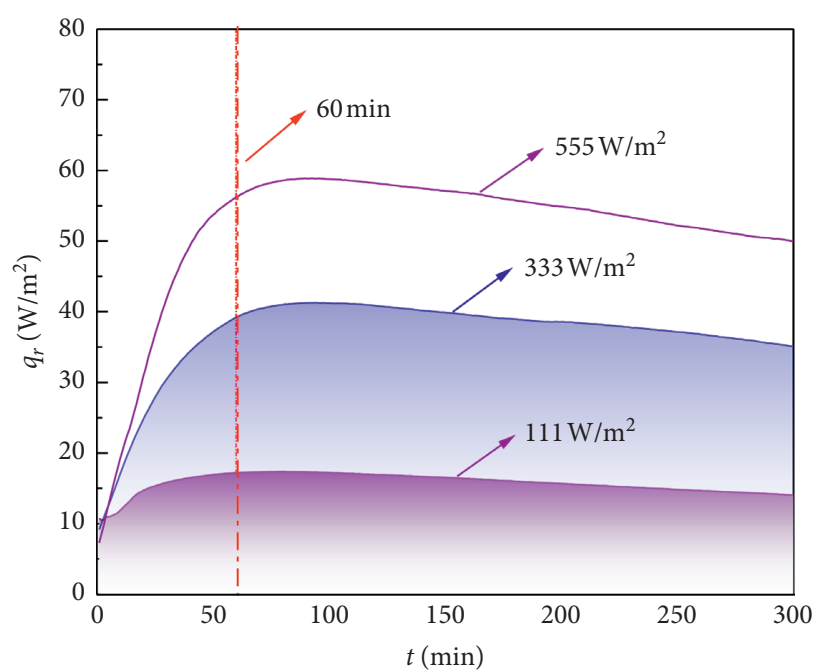

Figure 7: Cold radiation heats.

difference gradually decreases, but thermal efficiency does not decrease. The cold radiation heat flux generated by the ice-filled slurry region will always act on the simulated stope, and the ice particles in the ice-filled slurry region will start to melt, and the potential cooling capacity generated by the phase transition will decrease. Therefore, the cold radiation heat flux will show a decreasing trend.

3.4. Error Analysis. In the experimental process, the accuracy of the experimental instrument is the main reason which caused direct error. Temperature was measured by thermocouples and collected by the PXI system. The indirect error mainly comes from the calculation of the effective cooling heat coefficient. The maximum absolute error of the indirect measurement error can be calculated by the following equation:

$$
\Delta y=\frac{\partial f}{\partial x_{1}} \Delta x_{1}+\frac{\partial f}{\partial x_{2}} \Delta x_{2}+\cdots
$$

The error of the indirect measured boundary heating flux can be calculated by the error transfer formula from the following equations:

$$
\begin{gathered}
\frac{\partial q_{r}}{\partial T_{2}}=\varepsilon 6\left(4 T_{2}^{3}-T_{5}^{4}\right), \\
\frac{\partial q_{r}}{\partial T_{5}}=\varepsilon 6\left(T_{2}^{4}-4 T_{5}^{3}\right) .
\end{gathered}
$$

By analyzing the calculation results of the maximum relative error, the maximum relative error of cold radiation flux ranges from $4.38 \%$ to $4.77 \%$ are all less than $5 \%$.

\subsection{Influencing Factors and Variation Characteristics of Cold} Radiation Heat Flux. When judging the influence extent of different influencing factors on the heat flux of cold radiation, the average value of the heat flux of cold radiation at the same level of the same influencing factor is taken as the 
average heat flux of cold radiation. The influence extent of different factors on cold radiant heat flux could be obtained by comparing and analyzing the average heat flux of cold radiation.

3.5.1. Influence of Boundary Heat Flux. For analyzing the influence of boundary heat flux, the total cooling amount released from the ice-filled filling slurry region was different, even in the same proportion of the ice-filled slurry. As shown in Figure 8(a), with the higher boundary heat flux, the average cold radiation heat flux was higher. This is because the temperature in the simulated stope region increases rapidly with higher boundary heat flux. Finally, the heat flux of cold radiation increases with the increase of temperature difference.

3.5.2. Influence of Ice-Water Ratio. As shown in Figure 8(b), the greater the ice-water ratio was, the greater the extreme value of the average cold radiation heat flux would be. With the high ice-water ratio, the potential cooling capacity would be greater. However, at the end of the experiment, under the condition of the ice-water ratio was $5: 5$, the average cold radiant heat flux was greater than that of the ice-water ratio was $8: 5$. Because the peak of the average cold radiant heat flux appeared later, the ice-water ratio was $8: 5$. This time difference between the two peaks made the average cold radiation heat flux of ice-water ratio $5: 5$ condition exhibit higher in the later stage of the experiment.

3.5.3. Influence of Sand-Cement Ratio. As shown in Figure 8(c), the average cold radiant heat flux increases with the increase of sand-cement ratio. Larger sand-cement ratio indicated the mass of the cement contained in the filling slurry was lower. So, the hydration heat released by the cement in the hydration process was lower, and less cold is needed to absorb hydration heat. Therefore, the cooling radiation heat flux was greater. With the increase of sandcement ratio, the time of the extreme value of average cold radiant heat flux appeared later which is consistent with the analysis above.

3.5.4. Influence of Slurry Concentration. As can be seen from Figure $8(\mathrm{~d})$, the higher the slurry concentration was, the smaller the mean cold radiation heat flux was. The mass of ice particles will decrease with the increase of slurry concentration, which will lead to the decrease of potential cooling capacity. So, the average cold radiation heat flux is low most of the time. At the beginning of the experiment, the opposite pattern appeared. Owing to the greater hydration heat under the higher slurry concentration condition obviously at the beginning, the melting rate of ice particles was faster, and the cold radiant heat flux was higher.

According to the variation law of average cold radiation heat flux, it can be found that the boundary heat flux has the greatest influence on the cold radiation heat flux, because the value of boundary heat flux was much higher than that of cold radiant heat flux.

\section{Orthogonal Experimental Results and Discussions}

According to the orthogonal experimental scheme, ice-filled filling slurry was prepared in different proportion. The temperature data of several measuring points were obtained by continuously testing the ice-filled slurry in each ratio for 5 hours in the experimental device. The following results were obtained by analyzing and processing the temperature data.

4.1. Latent and Sensible Heat Transfer Characteristics of IceFilled Slurry. With the ice particle in the filling area melting, heat was absorbed during the melting process, and the temperature field of the filling region was affected. The icefilled slurry filling region was mainly influenced by phase change of ice particles, simulated surrounding rock heat flux and simulated stope region.

The Stephen number calculation results are shown in Figure 9. According to the Stephen number at different levels under different factors, when the boundary heat flux is $555 \mathrm{~W} / \mathrm{m}^{2}$, the Stephen number is larger than that of the lower heat flux conditions. In this case, the heat transfer of the sensible heat was much higher, because the temperature of simulated stope region was higher, and the total cold transferred to the stope was larger. With the increase of the ice-water ratio, the Stephen number decreases. The increase of ice particles increases the cold capacity and the latent heat of the filling slurry. From the perspective of sand-cement ratio, it has little influence on Stephen's number. The Stephen number increases with the increase in slurry concentration, indicating that the higher the slurry concentration was, the lower the latent cold of the slurry would be.

4.2. The Range Analysis of Orthogonal Test Results. According to the orthogonal experimental scheme, the appropriate evaluation index is selected and the orthogonal experimental results are evaluated and analyzed. In the experiment, the effective cooling heat coefficient was selected as the evaluation index, which was defined in equation (1), and the calculation results of the effective cooling heat coefficient were shown in Table 4.

According to the orthogonal experimental data processing method, the range analysis of the calculated evaluation index is carried out. Range analysis is called intuitive analysis, whose main purpose is to select the optimal level of each factor. If a better index value is required, select the corresponding level of the maximum average index. Otherwise, select the level corresponding to the minimum average index. The effective cooling heat coefficient is used as the evaluation index to calculate the range of each influencing factor, and the calculated results are shown in Table 5.

The influence of boundary heat flux on the effective cooling heat coefficient is the greatest, while the influence of slurry concentration on the effective cooling heat coefficient is the least. According to the principle that the greater the effective cooling heat coefficient the better, the degree of 


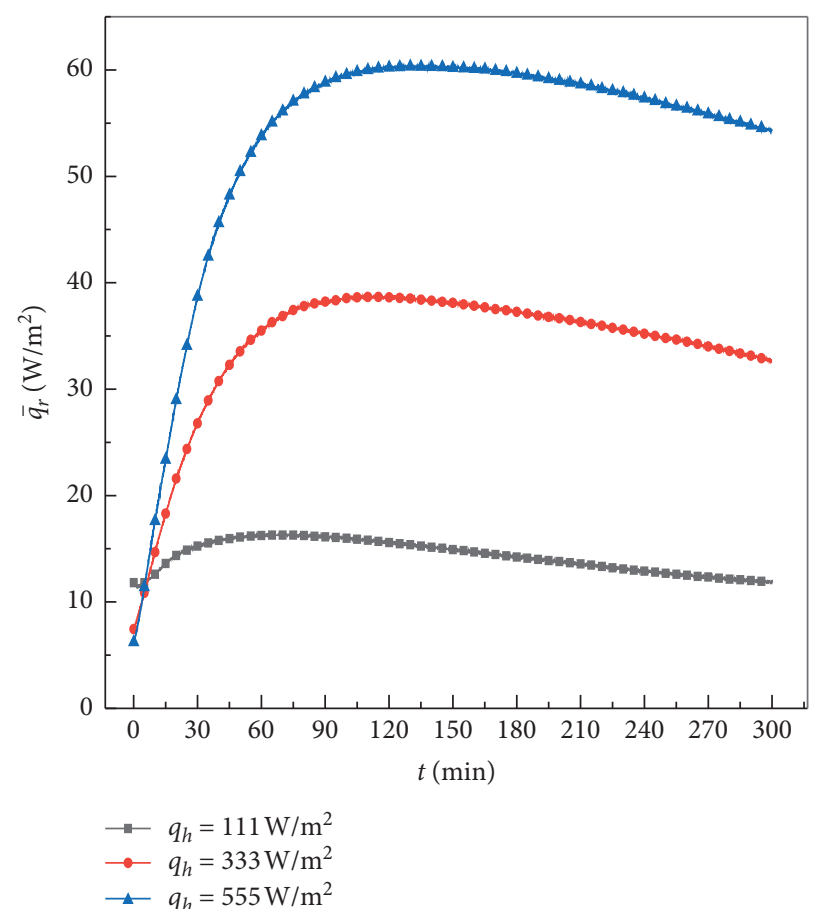

(a)

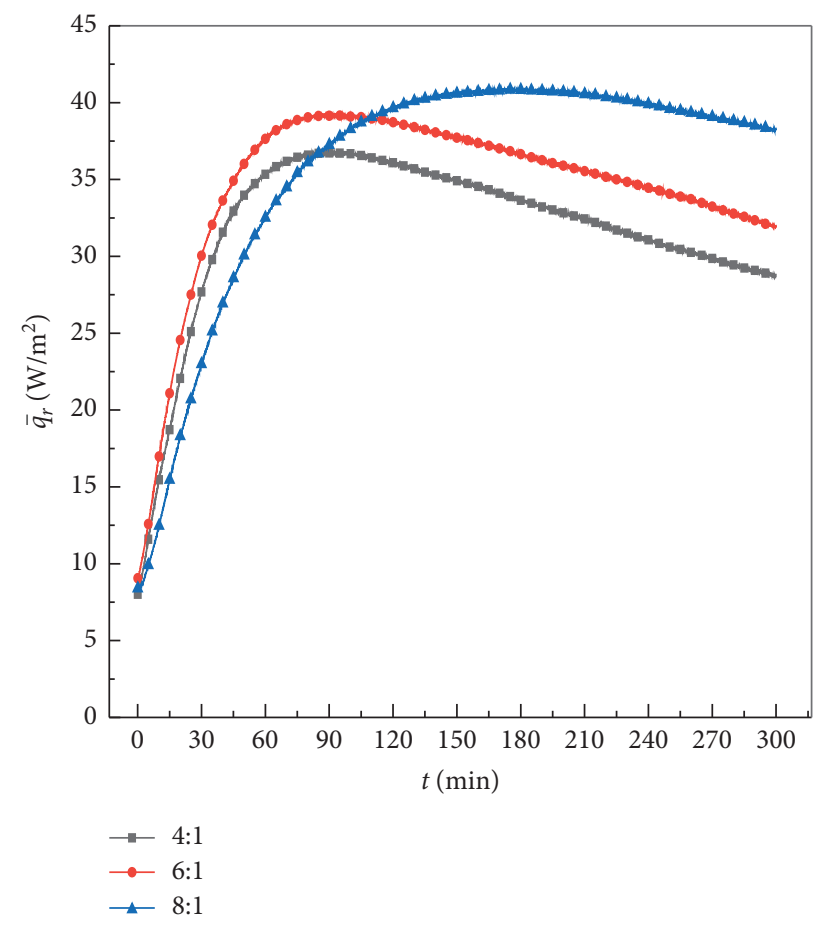

(c)

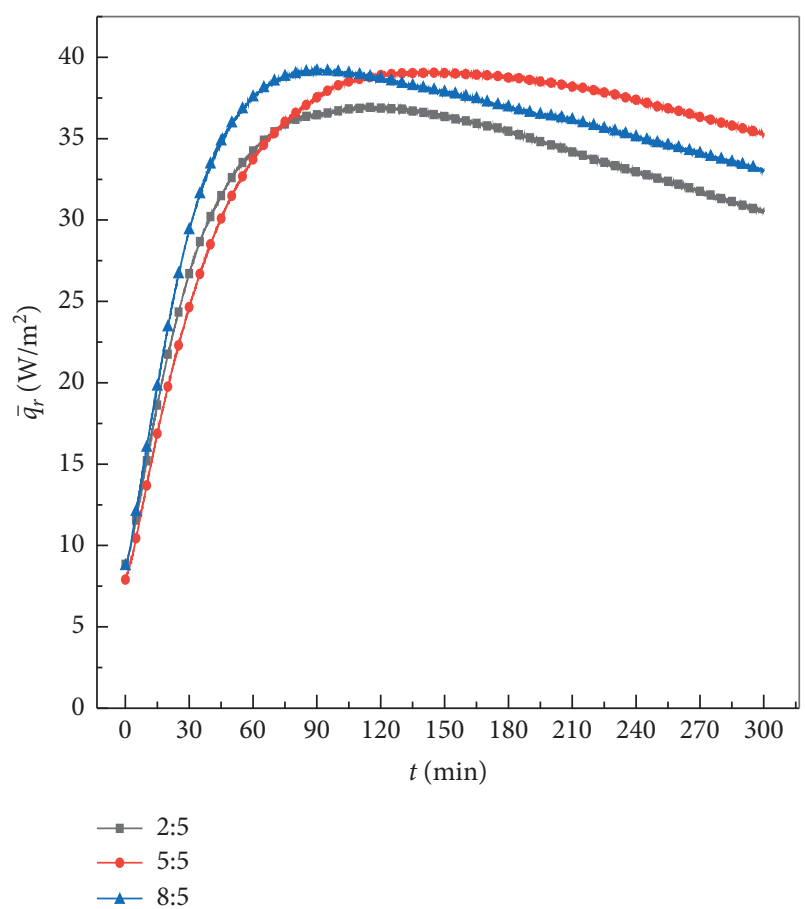

(b)

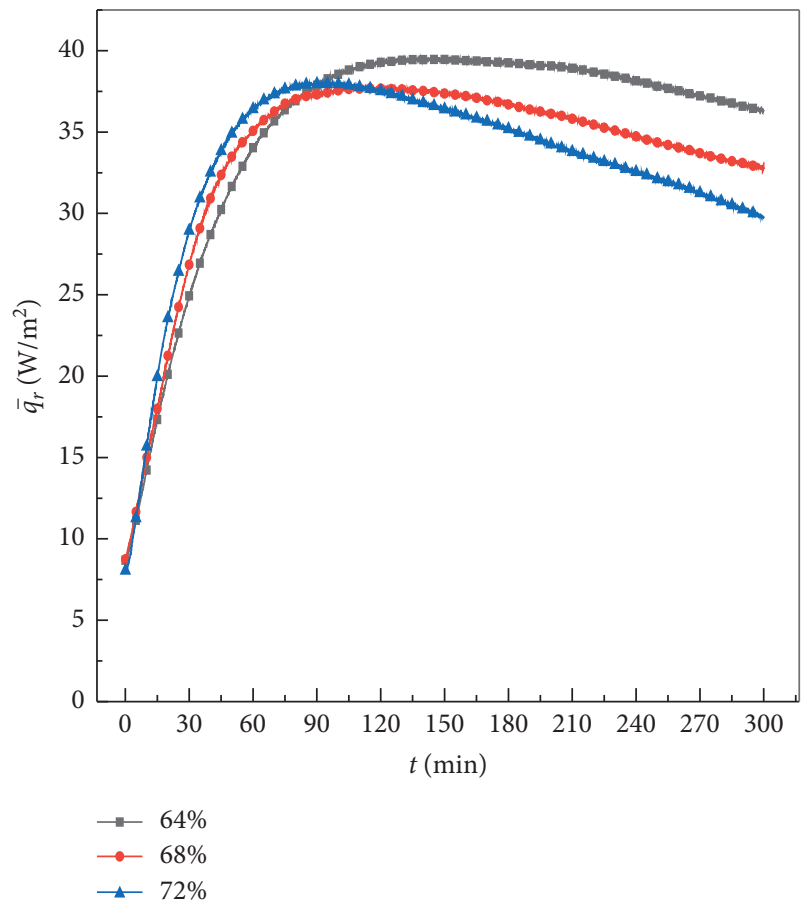

(d)

Figure 8: Mean cold radiation heat flow curve. (a) Influence of boundary heat flux. (b) Influence of ice-water. (c) Influence of sand-cement ratio. (d) Influence of slurry concentration.

influence of four factors was arranged from the greatest to the smallest in the order of boundary heat flux $>>$ ice-water ratio sand-cement ratio $>$ slurry concentration. According to the calculation results, the optimal combination of all factors was $A_{1} B_{3} C_{3} D_{2}$, when the boundary heat flux was $111 \mathrm{~W} / \mathrm{m}^{2}$, the ice-water ratio was $8: 5$, the sand-cement ratio was $4: 1$, and the slurry concentration was $68 \%$, and the effective cooling heat coefficient is the maximum.

4.3. Index Impact Analysis. According to the range analysis of orthogonal experimental results, as shown in Figure 10, 


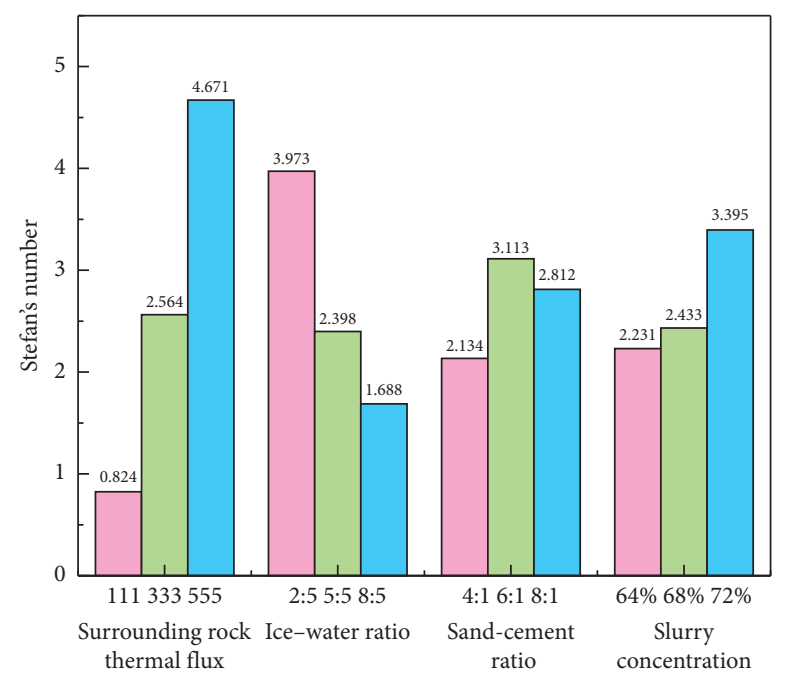

FIGURE 9: Stephen's number results.

TABLE 4: Orthogonal experimental results.

\begin{tabular}{|c|c|c|c|c|c|}
\hline \multicolumn{6}{|l|}{ Factors } \\
\hline $\begin{array}{l}\text { Experiment } \\
\text { number }\end{array}$ & $\begin{array}{l}\text { Surrounding rock heat flux A } \\
\qquad\left(\mathrm{W} / \mathrm{m}^{2}\right)\end{array}$ & $\begin{array}{l}\text { Ice-water } \\
\text { ratio B }\end{array}$ & $\begin{array}{l}\text { Sand-cement } \\
\text { ratio } C\end{array}$ & $\begin{array}{l}\text { Slurry concentration D } \\
(\%)\end{array}$ & $\begin{array}{c}\text { Heat-reducing coefficient } \\
\eta(\%)\end{array}$ \\
\hline 1 & 111 & $2: 5$ & $4: 1$ & 64 & 12.02 \\
\hline 2 & 111 & $5: 5$ & $6: 1$ & 68 & 15.95 \\
\hline 3 & 111 & $8: 5$ & $8: 1$ & 72 & 16.53 \\
\hline 4 & 333 & $2: 5$ & $8: 1$ & 68 & 11.46 \\
\hline 5 & 333 & $5: 5$ & $4: 1$ & 72 & 10.53 \\
\hline 6 & 333 & $8: 5$ & $6: 1$ & 64 & 12.37 \\
\hline 7 & 555 & $2: 5$ & $6: 1$ & 72 & 10.28 \\
\hline 8 & 555 & $5: 5$ & $8: 1$ & 64 & 11.51 \\
\hline 9 & 555 & $8: 5$ & $4: 1$ & 68 & 10.29 \\
\hline
\end{tabular}

TABLe 5: Analysis of the range of effective cooling heat coefficient.

\begin{tabular}{lccccc}
\hline Evaluation index & Value name & $\mathrm{A}(\%)$ & $\mathrm{B}(\%)$ & $\mathrm{C}(\%)$ & $\mathrm{D}(\%)$ \\
\hline \multirow{3}{*}{ Total } & $\mathrm{K} 1$ & 44.50 & 33.76 & 32.84 & 35.90 \\
& $\mathrm{~K} 2$ & 34.36 & 37.99 & 38.6 & 37.70 \\
& $\mathrm{~K} 3$ & 32.08 & 39.19 & 39.50 & 37.34 \\
\hline \multirow{3}{*}{ Average } & $\mathrm{k} 1$ & 14.83 & 11.25 & 10.95 & 11.97 \\
& $\mathrm{k} 2$ & 11.45 & 12.66 & 12.87 & 12.57 \\
Range & $\mathrm{k} 3$ & 10.69 & 13.06 & 13.17 & 12.45 \\
Ranking & & 4.14 & 1.81 & 2.22 & 0.6 \\
\hline Optimal & $A>C>B>D$ \\
combination & \multirow{5}{*}{$A 1 B 3 C 3 D 2$} \\
\hline
\end{tabular}

changes in boundary heat flux, ice-water ratio, and sandcement ratio caused large changes in the effective cooling heat coefficient, while slurry concentration has little influence, which was consistent with the results obtained by the range analysis of orthogonal experimental results in Table 4. In the orthogonal experiment, the selection level of the main factors will have a great impact on the experimental results, so there may exist errors between the degrees of the main

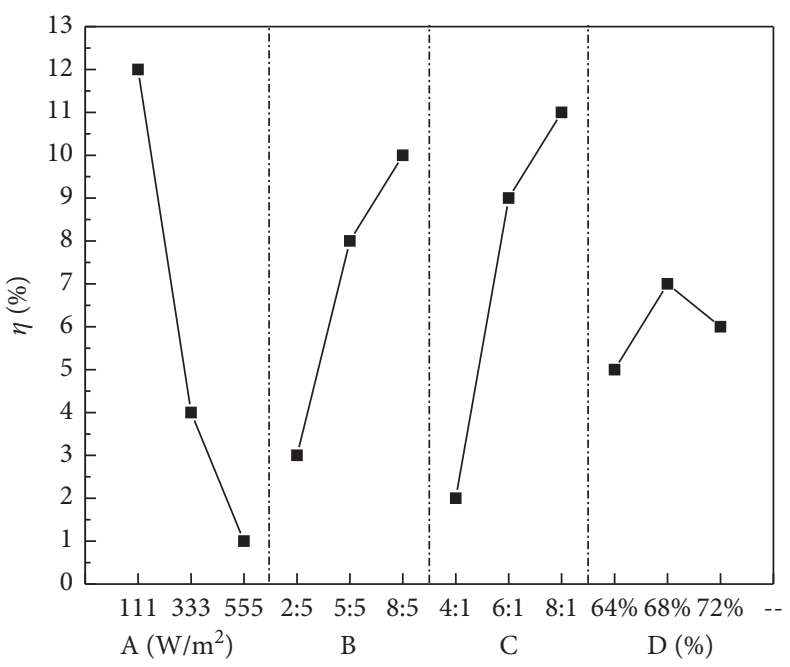

FIGURE 10: Variation trend of each factor.

factors. In this study, the effect of sand-cement ratio of effective cooling heat coefficient was greater than that of the ice-water ratio. 
By analyzing the definition of effective cooling heat coefficient, the variation trend mainly depends on the temperature of the simulated stope region and intermediate aluminum plate, while the temperature of the simulated stope area and the cooling degree of the intermediate aluminum plate are directly related to the proportion of icefilled filling slurry ratio.

Combining with the orthogonal experimental scheme, taking sand-cement ratio as the research object, the average ratio of ice to total mass of slurry was $15.5 \%$ under the condition of experiment number 1, 6, and 8, while taking the ice-water ratio as the research object, the value was $13.7 \%$ under the condition of experiment number 1,5 , and 9 . Because the effect of sand-cement ratio on effective cooling heat coefficient is higher than that of ice-water ratio. When the factor and the factor level change, the effective cooling heat coefficient changes, the effective cooling heat coefficient can indicate the cooling effect of the ice-filled slurry filling region on the simulated stope region under different ratios.

4.4. Ratio Optimized Design. The direct analysis results of the orthogonal experiment showed that as the effective cooling heat coefficient was taken as the evaluation index, the influence of boundary heat flux on cooling can be determined to be the greatest, and the effect is best when the boundary heat flux is $111 \mathrm{~W} / \mathrm{m}^{2}$. When the sand-cement ratio was $4: 1$, the average effective cooling heat coefficient was $16.86 \%$ lower than that of $8: 1$. So, the sand-cement ratio of $4: 1$ was selected. When the slurry concentration was $64 \%$, the average effective cooling heat coefficient was $4.77 \%$ lower than the slurry concentration of $68 \%$. In summary, the optimal ratio was the boundary heat flux at $111 \mathrm{~W} / \mathrm{m}^{2}$, the ice-water ratio at $8: 5$, the sand-cement ratio at $4: 1$, and the slurry concentration at $64 \%$.

\section{Conclusions}

The main factors on the cooling effect characteristics of the backfill slurry region with ice particles on the simulated stope region were studied by orthogonal experiment. The factors mainly included simulated surrounding rock heat flux, ice-water ratio, sand-cement ratio, and slurry concentration. By analyzing the measuring points temperature, the spatial and temporal characteristics of temperature variation in the two regions were obtained. In order to evaluate each factor, the effective cooling heat coefficient of the evaluation index was determined. Finally, the optimal ratio was obtained. The following conclusions can be drawn:

(1) Under adiabatic boundary condition, the cooling effect of the ice-filled slurry on the simulated stope region was obvious. Under the heating boundary conditions, the cooling effects were weakened by the increasing boundary heat flux. In order to guarantee the cooling effect in engineering, the cooling capacity and slurry ratio should be designed according to the actual heat flux of stope in practice.
(2) Under the same slurry concentration condition, the larger the ice-water ratio is, the better the cooling effect of the slurry is. Furthermore, under the same ice-water ratio, the higher the slurry concentration is, the lower the cooling effect of the slurry is.

(3) The effective cooling heat coefficient was defined for evaluating the cooling effect. The orthogonal test results indicated that the degree of influence of the four influencing factors in descending order was boundary heat flux > sand-cement ratio>ice-water ratio $>$ slurry concentration.

(4) Based on the results of interval analysis, the influence of different factors was comprehensively analyzed. In summary, the optimal ratios were heat flux of the simulated surrounding rock boundary heat flux at $111 \mathrm{~W} / \mathrm{m}^{2}$, ice-water ratio at $8: 5$, the sand-cement ratio at $4: 1$, and slurry concentration at $64 \%$.

In the future, mutual verification between experiment and numerical simulation will be carried out, thus promoting a wider application of the ice-filled filling slurry in the CPB analysis [40].

\section{Nomenclature}

T: $\quad$ Real-time temperature $(\mathrm{K})$

$T^{*}$ : Temperature difference under different conditions $(\mathrm{K})$

$\Delta T$ : Temperature change in different regions $(\mathrm{K})$

$L: \quad$ Latent heat of ice, $3.35 \times 10^{2} \mathrm{~kJ} / \mathrm{kg}$

$q_{r}$ : Cold radiation heat flux $\left(\mathrm{W} / \mathrm{m}^{2}\right)$

$\bar{q}_{r}$ : Mean cold radiant heat flux $\left(\mathrm{W} / \mathrm{m}^{2}\right)$

$\varepsilon$ : Emissivity of radiation

$\eta$ : $\quad$ Effective cooling coefficient

$m_{i}$ : Mass fraction of ice particles

$t$ : Time (min)

$D$ : Width of the bottom device, $0.3 \mathrm{~m}$

$\delta$ : Thickness of the bottom device

$T_{n}$ : Real-time temperature of measuring point, $n$ is the measuring point number $(K)$

$q_{h}$ : The boundary heat flux density of surrounding rock $\left(\mathrm{W} / \mathrm{m}^{2}\right)$

$c_{s}$ : Specific heat capacity of the ice-filled slurry, $1.544 \mathrm{~kJ} /$ $\mathrm{kg} \cdot \mathrm{K}$

$\lambda_{s}$ : Thermal conductivity coefficient of the ice-filled slurry, $0.6761 \mathrm{~W} / \mathrm{m} \mathrm{K}$,

$\sigma: \quad$ Stefan-Boltzmann constant, $5.67 * 10^{-8} \mathrm{w} / \mathrm{m}^{2} \cdot \mathrm{K}^{4}$.

\section{Data Availability}

The relevant data are provided in the article.

\section{Additional Points}

Ice particles were applied to the backfill for deep mine cooling. A set of experimental apparatus was established for testing the distribution of temperature field. The optimum ratio of backfill slurry was obtained by using the orthogonal test method. 


\section{Conflicts of Interest}

The authors declare that there are no conflicts of interest regarding the publication of this paper.

\section{Acknowledgments}

The authors are grateful for the support provided by the National Natural Science Foundation of China (nos. 51904224, 51974225, 51904225, and 52004207), the Natural Science Basic Research Plan in Shaanxi Province of China (nos. 2018JQ5183 and 2020JQ750), and Scientific Research Program Funded by Shaanxi Provincial Education Department of China (nos. 18JK0523 and 19JK0543).

\section{References}

[1] C. Song, G. Yu, and B. Xian, "A huge source of pollution hazard disaster and cure of tailings pond," in Proceedings of the International Conference on Electronics, Communications and Control (ICECC), pp. 3486-3489, Ningbo, China, September 2011.

[2] J. Zhang, Q. Zhang, Q. Sun, R. Gao, D. Germain, and S. Abro, "Surface subsidence control theory and application to backfill coal mining technology," Environmental Earth Sciences, vol. 74, no. 2, pp. 1439-1448, 2015.

[3] M. Wang, L. Liu, B. Zhang et al., "The basic going of cold load and storage functional backfill mining," Journal of China Coal Society, vol. 45, no. 4, pp. 1336-1347, 2020.

[4] G. R. Pathegama, J. Zhao, M. Ju et al., "Opportunities and challenges in deep mining: a brief review," Engineering, vol. 4, pp. 546-551, 2017.

[5] Z.-g. Su, Z.-a. Jiang, and Z.-q. Sun, "Study on the heat hazard of deep exploitation in high-temperature mines and its evaluation index," Procedia Earth and Planetary Science, vol. 1, no. 1, pp. 414-419, 2009.

[6] M. Fourier, T. Belem, A. Fourie et al., "Time-dependent failure criterion for cemented paste backfills," in Proceedings of the Richard Jewell and Andy Fourier: Proceeding of the 13th International Seminar on Paste and Thickened Tailings, pp. 147-162, Toronto, Canada, May 2010.

[7] X. Chen, J. Zhou, Q. Chen, X. Shi, and Y. Gou, "CFD simulation of pipeline transport properties of mine tailings threephase foam slurry backfill," Minerals, vol. 7, no. 8, p. 149, 2017.

[8] A. Kemal, E. Yilmaz, B. Ericikdi et al., "Effect of the properties of tailings and binder on the short-and long-term strength and stability of cemented paste backfill," Materials Letters, vol. 59, no. 28, pp. 3703-3709, 2005.

[9] D. Wu, Y. Zhang, and Y. Liu, "Mechanical performance and ultrasonic properties of cemented gangue backfill with admixture of fly ash," Ultrasonics, vol. 64, pp. 89-96, 2016.

[10] M. Wang, L. Liu, L. Chen, X. Zhang, B. Zhang, and C. Ji, "Cold load and storage functional backfill for cooling deep mine," Advances in Civil Engineering, vol. 2018, 8 pages, 2018.

[11] M. Wang, L. Liu, X.-Y. Zhang, L. Chen, S.-Q. Wang, and Y.-H. Jia, "Experimental and numerical investigations of heat transfer and phase change characteristics of cemented paste backfill with PCM," Applied Thermal Engineering, vol. 150, no. 5, pp. 121-131, 2019.

[12] Q. Chen, Q. Zhang, C. Qi et al., "Recycling phosphogypsum and construction demolition waste for cemented paste backfill and its environmental impact," Journal of Cleaner Production, vol. 186, 2018.
[13] X. Zhang, Y. Jia, M. Wang, and L. Liu, "Experimental research on heat transfer and strength analysis of backfill with ice grains in deep mines," Sustainability, vol. 11, no. 9, p. 2486, 2019.

[14] X. Zhang, D. Wen, Y. J. Zhao et al., "Mine heat storage/energy storage research on heat transfer and mechanical properties of functional filling body [J/OL]," Journal of Coal, pp. 1-14, 2021.

[15] Z. Y. Fang, Investigation on the Flow and Settlement Law of Ice-Containing Cemented Paste Backfill Slurry in High Temperature and Deep Well, Xi'an University of Science and Technology, Xi'an, China, 2020.

[16] X. Hu, L. Liu, G. Li et al., "Study on optimal ratio of mine filling-based on uniform test," Mining Research and Development, vol. 35, no. 3, pp. 7-12, 2015.

[17] Z. Fan, J. Men, C. Gong et al., "Experimental study on the proportioning of unclassified tailings paste based on the requirement of high strength backfill body," Journal of Safety Science and Technology, vol. 14, no. 12, pp. 102-106, 2018.

[18] R. Men and C. Xie, "Numerical and experimental Study on filling ratio of complete tailings paste," Mining Research and Development, vol. 38, no. 12, pp. 28-31, 2008.

[19] F. Feng, D. Li, X. Li et al., "Novel underhand cut-and-fill stoping method and mechanical analysis of overlying backfill," International Journal of Geomechanics, vol. 17, no. 7, Article ID 4017004, 2017.

[20] Z. E. Muhammad, M. Hani, and K. Cecile, "State-of-the-art review backfill practices for sublevel stoping system," International Journal of Mining, Applications and Environment, vol. 29, no. 6, pp. 544-556, 2015.

[21] M. Fall and M. Benzaazoua, "Modeling the effect of sulphate on strength development of paste backfill and binder mixture optimization," Cement and Concrete Research, vol. 35, no. 2, pp. 301-314, 2005.

[22] J.-p. Li, C.-l. Du, and G.-1. Teng, "Experimental of pumping gangue into the mined-out area," Procedia Earth and Planetary Science, vol. 1, no. 1, pp. 760-765, 2009.

[23] L. Liu, Z. Y. Fang, Y. P. Wu, X. P. Lai, P. Wang, and K.-I. Song, "Experimental investigation of solid-liquid two-phase flow in cemented rock-tailings backfill using Electrical Resistance Tomography," Construction and Building Materials, vol. 175, pp. 267-276, 2018.

[24] Y. Liu, C. Lu, H. Zhang, and J. Li, "Experimental study on chemical activation of recycled powder as a cementitious material in mine paste backfilling," Environmental Engineering Research, vol. 21, no. 4, pp. 341-349, 2016.

[25] D. Y. Wei, Hydration Heat Production Law and Ventilation and Cooling Prediction Model of Cemented Backfill, Beijing University of Science and Technology, Beijing, China, 2021.

[26] D. Zhang, N. Cai, X. Cui, X. Xia, J. Shi, and X. Huang, "Experimental investigation on model predictive control of radiant floor cooling combined with underfloor ventilation system," Energy, vol. 176, pp. 23-33, 2019.

[27] H. Tang, T. Zhang, X. Liu et al., "Novel method for the design of radiant floor cooling systems through homogenizing spatial solar radiation distribution," Solar Energy, vol. 170, pp. 885-895, 2008.

[28] D. Deng, Z. Yao, and Y. Yang, "Study on Permeability of highdensity cement-tailing backfill," Nonferrous Metals, vol. 58, no. 2, pp. 87-90, 2006.

[29] W. Bai, J. Zhang, P. Yan, and X. Wang, "Study on vibration alleviating properties of glass fiber reinforced polymer concrete through orthogonal tests," Materials \& Design, vol. 30, no. 4, pp. 1417-1421, 2009. 
[30] X. Zhou, X. Chen, J. Shi et al., "The feasibility of process ultrafine leaching residue by backfill: experimental and CFD approaches," Journal of Minerals, vol. 7, no. 4, p. 54, 2017.

[31] P. Olivier and B. Mostafa, "Alternative by-product -based binders for cemented mine backfill: recipes optimisation using taguchi method," Minerals Engineering, vol. 29, pp. 28-38, 2012.

[32] Y. Xiang, Y. Zhang, Y. Guo et al., "Study on the strength of filling body with unclassified tailings based on orthogonal experiment," Mining Research and Development, vol. 27, no. 1, pp. 27-29, 2017.

[33] D. Q. Deng, L. Liu, Z. L. Yao, K. I.-I. L. Song, and D. Z. Lao, “A practice of ultra-fine tailings disposal as filling material in a gold mine," Journal of Environmental Management, vol. 196, pp. 100-109, 2017.

[34] S. M. Yang and W. Q. Tao, Heat transfer, Higher Education Press, Beijing, China, 2006.

[35] China Coal Industry Publishing House, AQ 2013.1-2008. Technical Standards for Metal and Nonmetal Underground Mines, Windows, China Coal Industry Publishing House, Beijing, China, 2001.

[36] G. Han, H. Ding, P. Wang et al., "Numerical simulation on performance enhancement of eccentric fin-tube latent heat storage unit," Energy Storage Science and Technology, vol. 4, no. 02, pp. 183-188, 2015.

[37] F. Guo, Dynamic Heat Transfer, 1997.

[38] Proceedings of the Chinese Society of Engineering Thermo Physics Academic Conference on Heat and Mass Transfer, Beijing, China, 2006.

[39] J. H. Yan and L. P. Zhang, Progress in Energy and Environment Research, Zhejiang University Press, Hangzhou, China, 2008.

[40] S. Akio, U. Yoshio, and T. Yasuji, "On contact heat transfer with melting (the melting on the inner surface of a horizontal cylindrical tube)," vol. 31, no. 1, pp. 58-65, 1988. 